\title{
Intimate partner violence and uptake of HIV testing and STI treatment among married women in Nigeria
}

\author{
Ifeyinwa E. Udo ${ }^{1}$, Henry V. Doctor ${ }^{2}$ \& Babatunde A. Ahonsi ${ }^{3}$. \\ ${ }^{1}$ Center for Interdisciplinary Research on AIDS \\ Yale University School of Public Health, New Haven, Connecticut, USA \\ ${ }^{2}$ World Health Organization \\ Regional Office for the Eastern Mediterranean, Cairo, Egypt \\ ${ }^{3}$ United Nations Population Fund, Beijing, China \\ ifyudo@gmail.com
}

\begin{abstract}
Context/Background: Nigeria has a high prevalence of Intimate Partner Violence (IPV) and STls including HIVIAIDS - which constitute a major public health problem.

Data Sources and Methods: This study examines the association between IPV, uptake of HIV testing and STI treatment and their correlates among married women of reproductive age, with recent STI, using the 2013 Nigeria DHS Data.

Results: We observed high prevalence of any IPV (60\%), lower prevalence of HIV testing uptake (20\%) and higher prevalence of STI treatment (74\%). There was reduced odds of HIV testing uptake and increased odds of STI treatment among women who experienced IPV, but these were not statistically significant. Education and health facility visit were associated with HIV testing uptake while wealth quintile and autonomy were associated with STI treatment.

Conclusion: There is need to improve early identification of women at risk of experiencing IPV, understand the barriers to HIV testing uptake and STI treatment and intervene early.
\end{abstract}

Keywords: HIV, STI, Intimate Partner Violence, Autonomy

\section{Introduction}

Intimate Partner Violence (IPV) is a global health problem that adversely affects the health of women. In Nigeria, IPV against women is common and widespread. A recent study found a prevalence rate of $42 \%$ for any type of IPV among women attending a tertiary institution in Nigeria and studies in different states have found generally high rates of IPV across all regions in Nigeria (Umana, Fawole and Adeoye, 2014; Bamiwuye and Odimegwu, 2014; Tanimu, Yohanna and Omeiza, 2016). These findings are consistent with results from the 2013 Demographic Health Survey (DHS) which show that $25 \%$ of ever married women aged 15-49 years have experienced either emotional, physical and/or sexual violence from a spouse, with $19 \%$ ever experiencing one or more forms of these violence in the 12 months prior to the survey (National Population Commission (NPC) [Nigeria] and ICF International, 20I4). The high prevalence of IPV presents a big challenge for women's sexual health sexual and reproductive health.

Literature review and theoretical framework IPV occurs because of gender power imbalances between men and women that often leaves women 3855 with less autonomy and control over their sexual health and other areas of their lives (Teitelman et al. 2015). Women with history of IPV are almost 3 times more likely to have had a sexually transmitted Infection (STI) compared to their non-abused counterparts (Teitelman et al. 2015).

Women experiencing IPV may be afraid of discussing condom use with their partners, thereby increasing their risk of STls, if they have high-risk partners. Studies show that women who are victims of IPV are more likely to engage in risky behaviors such as unprotected sex, condom non-use, and multiple sexual partnerships. Consequently, these women are at higher risk of contracting STIs including HIV, suggesting the importance of preventive services for this group of women (McGrane Minton et al. 2016; Manfrin-Ledet, Porche and Westbrook, 2015; Overstreet et al. 2015; Udo et al. 2016).

The 20I3 DHS survey from Nigeria shows that the prevalence of STI or symptoms of STI ranged from $0.7 \%$ in Kwara State to as high as $23.5 \%$ in Benue State, with $27 \%$ of all women reporting STI not seeking any form of treatment or advice. About HIV, Nigeria is one of the 15 countries in sub Saharan Africa that account for $75 \%$ of the global HIV http://aps.journals.ac.za 
infection burden, with an adult HIV prevalence of 2.9\%. In absolute terms, Nigeria has the second largest HIV epidemic in the world and records one of the highest new infections in sub Saharan Africa (Kharsany and Karim, 2016; UNAIDS 20I4). Other countries with high adult HIV prevalence include South Africa (I8.9\%), Zimbabwe (I3.5\%), Zambia (I2.4\%), Mozambique (12.3\%), Malawi (9.2\%), Uganda (6.5\%), Kenya (5.4\%), Tanzania (4.7\%), and Ethiopia (I.1\%) (Kharsany and Karim, 2016; UNAIDS 2014). According to a recent UNAIDS report, only about $45 \%$ of people living with HIV in sub Saharan Africa know their HIV status, indicating low rates of HIV testing in this region (UNAIDS 2014). Knowledge of HIV status is crucial as it enables individuals make informed decisions about adopting sexual health behaviors to reduce their risk of contracting or transmitting HIV.'

According to the 2013 DHS survey in Nigeria, about $70 \%$ of women had never tested for HIV (National Population Commission (NPC) [Nigeria] and ICF International 20I4). HIV testing is a key prevention strategy for HIV infection. Increasing the uptake of HIV testing and STI treatment are both primary and secondary prevention measures. As a primary prevention measure, HIV testing and STI treatment prevents HIV/STI transmission to uninfected people. For secondary prevention, testing and treatment reduce the risk of more adverse outcomes from the disease. These may not be practices of women who are in abusive relationships, who do not have the autonomy to seek HIV testing on their own without their partner's consent. However, some studies have shown increased STI testing among women with recent IPV and reproductive coercion experience (Kazmerski et al. 20I5).

The influence of gender and power imbalances on IPV risk among women can be aptly conceptualized with the gender analysis framework, which analyzes the norms and different roles that men and women play in the society and the impact of these differences on their lives (Jhepiego, 2018). According to the framework, the 4 domains that are key for assessing gender differences include: i) access to assets which includes how gender relations affect access to resources (tangible and intangible) necessary for a person to be a productive member of the society; ii) beliefs and perceptions which include beliefs and norms about what it is to be a man or woman in a particular society which in turn affects men's and women's behaviors, participation and decision making power; iii) practice and participation in the society as affected and influenced by gender norms; iv) institutions, laws and policies which shape the extent to which institutional policies and stipulations affect men and women differentially. At the center of this framework is power, which cuts across all the domains and determines who can purchase and expend assets, who makes decisions in the society at the different levels including the family. Power also determines the rights that an individual can exercise and consequently, determines who can acquire asset and make decisions in the society.

Findings from the 2013 Nigerian DHS show gender gaps (with women lagging) along these domains, which negatively affect the health and wellbeing of women. For example, fewer women (24\%) have comprehensive knowledge about HIV/AIDS than men (34\%), fewer women (60\%) know where to get an HIV test than men (7I\%), fewer women $(7 \mid \%)$ are employed than men (99\%), and a lot more women (82-85 \%) do not own an asset (house or land) compared to men (60-66\%). Furthermore, only $6 \%$ of married women make decisions about their own healthcare compared to $65 \%$ of men who do and $34 \%$ of women justify wife beating by their partners. Lack of access to and knowledge about HIV preventive behaviors, low income and asset ownership, and less autonomy and endorsement of IPV would tend to increase women's vulnerability to IPV and STIs including HIV/AIDS in Nigeria.

In sum, while some evidence exist on the possible causal relationships between IPV and STI (HIV) risk factors, STI treatment and uptake of HIV testing, more studies examining these relationships in sub Saharan African contexts are clearly needed ( $\mathrm{Li}$ et al. 20I4; Hess et al. 20I2).

Considering the existing evidence on the association between IPV and STI/HIV risk, the high prevalence of IPV and STIs in Nigeria, and the low uptake of HIV testing, especially among married women of reproductive age, it is imperative to develop integrated prevention and control interventions. These interventions should address IPV as a common risk factor for HIV and STI infection while also addressing factors that promote gender inequalities and inequities. Developing such interventions will benefit from better understanding of the association between IPV and HIV preventive health behaviors such as HIV testing and STI treatment, particularly among women at increased risk for HIV, such as those with recent STI infection. Furthermore, given that these women have increased risk for contracting STIs, it is important that they stay connected to the health system. This provides opportunity for early identification and treatment of STIs, and linkage to other necessary services, including regular HIV testing and IPV risk mitigation services. 
Taken together, the current study aims to close the extant knowledge gap by i) examining the association between IPV experience and uptake of HIV testing and STI treatment among married women with recent STI infection, using the 2013 Nigeria DHS and ii) examining the correlates of uptake of HIV testing and STI treatment among this group.

\section{Data and methods}

\section{Data source}

We used publicly de-identified individual-level data from the 2013 Nigeria DHS, a nationally representative population-based survey with a historical focus on fertility, mortality and reproductive health but which also collects data on women's autonomy and IPV. The DHS Program is largely funded by the U.S. Agency for International Development and the data offer various indicators to assess progress in improving maternal and child health. The 20I3 DHS sample was selected using a stratified three-stage cluster design consisting of 904 clusters (372 urban; 532 rural). A representative sample of 40,320 households were selected for the survey with a minimum target of 943 completed interviews per state, for each of the 36 states and the Federal Capital Territory, Abuja. All women ages I549 who were either permanent residents or visitors in the households on the night before the survey were eligible to be interviewed. In a sub-sample of half of the households, all men ages 15-49 were also interviewed. A sub-sample of one eligible woman in each household was randomly selected to respond to questions on IPV (domestic violence).

For the current study, 27,274 out of 38,948 eligible women were currently married or cohabiting at the time of the survey. Of the 27,274 women, 834 $(n=3.1 \%)$ reported having had an STI in the 12 months preceding the survey; out of which 768 had valid responses on whether they sought help for STI or ever had an HIV test. Our final sample consisted of 768 married women reporting an STI infection during the 12 months preceding to the survey. Figure I presents a summary of the initial sample, the number of excluded observations, the reasons for exclusion and the final analytical sample. 
Total number of women ages 15-49 from

the representative sample of 40,320

households selected for the 2013 Nigeria

Demographic and Health Survey $=38,948$

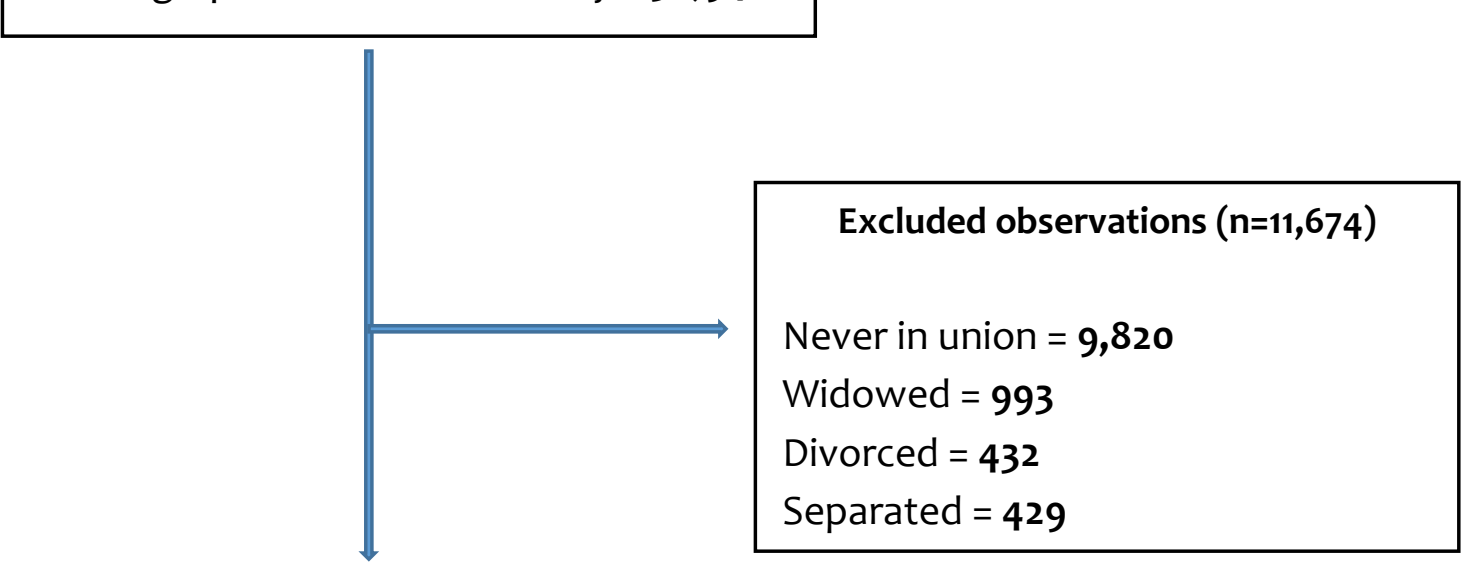

Currently in union at the time of survey

$(n=27,274)$

Married $=\mathbf{2 6 , 4 0 3}$

Cohabiting $=\mathbf{8 7 1}$

\section{Figure 1:Flow Diagram of Sample Selection}

\section{Variables}

The main independent variable, IPV, is a categorical variable. It assessed women's experience of emotional, physical, and sexual violence or no IPV experience. Specifically, emotional IPV was defined by a series of questions that asked women to assess whether their current husband/partner had ever humiliated, threatened (with a knife/gun or other weapon) or insulted them. Physical IPV was assessed by asking women if their husbands/partners had ever pushed, slapped, punched, kicked, strangled or ever had their arm-twisted or their hair pulled. Sexual IPV was assessed by responses to whether the husband/partner forced the woman into other unwanted sexual acts. From these questions, IPV was
Included observations

Had a sexually transmitted infection (STI) in the 12 months preceding the survey $=834$

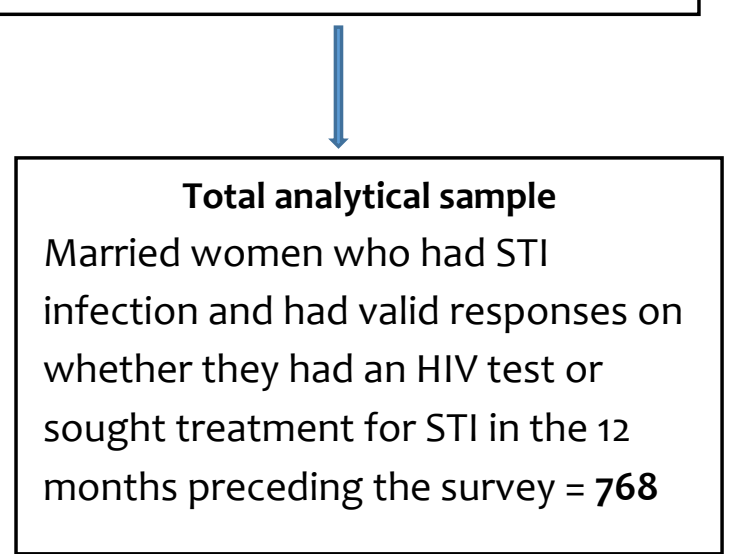

coded as "I" if a woman answered in the affirmative to at least one of the questions and " 0 " otherwise.

Other independent (control) variables adjusted for in the analysis include: education (none, primary, secondary), household wealth quintile, place of residence (urban/rural), religion (Christianity, Islam, and other), age, access to health services measured by whether woman visited health facility during the 12 months preceding the survey, and autonomy assessed by asking women who made decisions about woman's healthcare (woman alone, woman and her husband/partner and husband or others). Women who reported making this decision by themselves or jointly with their partners were coded as "I" for autonomous and "0" otherwise. These variables were included in the analysis based on evidence of 
their association with IPV, HIV testing uptake and STI treatment (Bonnes 20I6; Butsashvili et al. 2014; Mahande, Phimemon and Ramadhani, 2016; Gazimbi and Monica, 20I7).

The dependent variables for the study are HIV testing uptake assessed by asking women if they had ever been tested for HIV (Yes/No). A follow up question was asked about how many months ago had passed since their last HIV testing. We defined HIV testing uptake as HIV testing that occurred in the last 12 months preceding the survey. Women that had not been tested for HIV in the 12 months preceding the survey were categorized as having no HIV testing uptake. STI treatment was assessed by asking the women if they sought any kind of advice or treatment for their STI. Women that reported seeking any form of STI treatment were coded as "I" for yes and " 0 " otherwise.

\section{Statistical methods}

Statistical analyses were conducted in Stata 14 via survey procedures including weights to account for the multistage survey design used in the DHS. The distributions among women with respect to uptake of HIV, STI treatment and socio-demographic characteristics were compared using chi-square contingency tables and applying weighted frequencies. To determine the association between uptake of HIV testing, STI treatment and multiple predictor variables, we used logistic regression model to estimate the magnitude of association in form of odds ratios (ORs) between the dependent variables and selected predictor variables.

\section{Results}

Table I shows the demographic characteristics of women by HIV testing uptake and STI treatment. The prevalence of any form of IPV in the sample was $60 \%$. Sexual IPV was the most prevalent (27\%) followed by physical IPV (19\%), while emotional IPV (I4\%) was the least prevalent form of IPV reported among the women. IPV prevalence was generally higher among women with no HIV testing uptake $(63 \%)$ than among women with HIV testing uptake (5I\%). We observed almost same IPV prevalence among women who sought help with their recent STI, and those who did not $(60 \%$ and $61 \%$ respectively). 
African Population Studies Vol. 32, No. I, 2018

Table I. Demographic characteristics of married women with recent STI infections, by uptake of HIV testing and STI treatment during the 12 months prior to the Nigeria Demographic and Health Survey, 2013

Weighted percentages

\begin{tabular}{|c|c|c|c|c|c|c|c|c|}
\hline \multirow{2}{*}{ Characteristics } & \multicolumn{4}{|c|}{ Uptake of HIV testing } & \multicolumn{3}{|c|}{ Sought help during last STI infection } & \multirow[t]{2}{*}{ Total } \\
\hline & No & Yes & P-value & Total & No & Yes & P-value & \\
\hline \multicolumn{9}{|c|}{ Intimate partner violence } \\
\hline None & 37.4 & 49.2 & 0.375 & 39.7 & 39.5 & 40.2 & 0.812 & 40.0 \\
\hline Emotional & 14.7 & 11.2 & & 14.0 & 12.7 & 14.3 & & 13.9 \\
\hline Physical & 20.2 & 14.4 & & 19.1 & 20.3 & 18.6 & & 19.1 \\
\hline Sexual & 27.8 & 25.2 & & 27.3 & 27.5 & 26.9 & & 27.1 \\
\hline \multicolumn{9}{|c|}{ Experienced any IPV } \\
\hline No & 37.4 & 49.2 & 0.089 & 39.7 & 39.5 & 40.2 & 0.464 & 40.0 \\
\hline Yes & 62.6 & 50.8 & & 60.3 & 60.5 & 59.8 & & 60.0 \\
\hline \multicolumn{9}{|c|}{ Place of residence } \\
\hline Urban & 44.2 & 57.6 & 0.114 & 56.1 & 42.8 & 61.5 & 0.000 & 56.3 \\
\hline Rural & 55.8 & 42.4 & & 43.9 & 57.2 & 38.5 & & 43.7 \\
\hline \multicolumn{9}{|l|}{ Age group } \\
\hline $15-24$ & 15.6 & 15.1 & 0.003 & 15.5 & 13.6 & 16.0 & 0.002 & 15.3 \\
\hline $25-34$ & 41.7 & 56.6 & & 44.6 & 37.7 & 48.0 & & 45.1 \\
\hline $35-49$ & 42.7 & 28.3 & & 39.9 & 48.7 & 36.0 & & 39.5 \\
\hline Mean age (SD) & $33.1(8.0)$ & $31.1(6.6)$ & & $32.6(7.8)$ & $34.2(8.09)$ & $32.0(7.57)$ & & $32.6(7.77)$ \\
\hline \multicolumn{9}{|c|}{ Region of residence } \\
\hline North Central & 10.6 & 21.7 & 0.000 & 12.7 & 8.6 & 14.4 & 0.000 & 12.8 \\
\hline North East & 9.6 & 10.6 & & 9.8 & 6.8 & 10.9 & & 9.8 \\
\hline North West & 53.7 & 16.7 & & 46.6 & 67.9 & 37.8 & & 46.1 \\
\hline South East & 15.9 & 27.4 & & 18.2 & 9.1 & 22.3 & & 18.7 \\
\hline South South & 3.3 & 9.1 & & 4.4 & 3.3 & 4.8 & & 4.3 \\
\hline South West & 7.0 & 14.5 & & 8.4 & 4.4 & 9.9 & & 8.3 \\
\hline
\end{tabular}


African Population Studies Vol. 32, No. I, 2018

\section{Weighted percentages}

\begin{tabular}{|c|c|c|c|c|c|c|c|c|}
\hline \multirow{2}{*}{ Characteristics } & \multicolumn{4}{|c|}{ Uptake of HIV testing } & \multicolumn{3}{|c|}{ Sought help during last STI infection } & \multirow[t]{2}{*}{ Total } \\
\hline & No & Yes & P-value & Total & No & Yes & P-value & \\
\hline \multicolumn{9}{|l|}{ Wealth quintile } \\
\hline Lowest & 9.7 & 6.6 & 0.000 & 9.1 & 17.0 & 5.9 & 0.000 & 9.0 \\
\hline Second & 22.9 & 12.7 & & 20.9 & 38.9 & 14.0 & & 20.9 \\
\hline Third & 18.3 & 18.8 & & 18.4 & 15.5 & 19.4 & & 18.3 \\
\hline Fourth & 25.6 & 21.7 & & 24.9 & 17.9 & 28.0 & & 25.2 \\
\hline Highest & 23.5 & 40.2 & & 26.7 & 10.7 & 32.8 & & 26.6 \\
\hline \multicolumn{9}{|l|}{ Education } \\
\hline None & 32.6 & 13.8 & 0.000 & 29.0 & 52.3 & 19.7 & 0.000 & 28.7 \\
\hline Primary & 22.8 & 18.3 & & 21.9 & 18.8 & 22.9 & & 21.8 \\
\hline Secondary and higher & 44.6 & 67.9 & & 49.1 & 28.9 & 57.4 & & 49.5 \\
\hline \multicolumn{9}{|l|}{ Religion } \\
\hline Christianity & 62.6 & 79.1 & 0.000 & 65.8 & 51.1 & 71.6 & 0.000 & 65.9 \\
\hline Islamhad & 36.6 & 20.8 & & 33.5 & 48.6 & 27.5 & & 33.4 \\
\hline Other $^{\mathrm{a}}$ & 0.8 & 0.2 & & 0.7 & 0.3 & 0.8 & & 0.7 \\
\hline \multicolumn{9}{|c|}{$\begin{array}{l}\text { Visited health facility (last I } 2 \\
\text { months) }\end{array}$} \\
\hline No & 53.7 & 47.6 & 0.002 & 52.5 & 62.8 & 48.0 & 0.000 & 52.1 \\
\hline Yes & 46.3 & 52.4 & & 47.5 & 37.3 & 52.0 & & 47.9 \\
\hline \multicolumn{9}{|l|}{ Autonomy } \\
\hline No & 45.6 & 48.2 & 0.601 & 46.2 & 58.9 & 40.7 & 0.000 & 45.9 \\
\hline Yes & 54.4 & 51.8 & & 53.9 & $4 I .1$ & 59.3 & & 54.2 \\
\hline \multicolumn{9}{|l|}{$\begin{array}{l}\text { Knows a place to get HIV } \\
\text { test }\end{array}$} \\
\hline No & 13.3 & 0.0 & 0.000 & 10.8 & 18.9 & 7.5 & 0.000 & 10.7 \\
\hline Yes & 86.7 & 100.0 & & 89.2 & 81.1 & 92.5 & & 89.3 \\
\hline
\end{tabular}

Used condoms I 2 months 
Weighted percentages

\begin{tabular}{|c|c|c|c|c|c|c|c|c|}
\hline \multirow{2}{*}{$\begin{array}{l}\text { Characteristics } \\
\text { before survey }\end{array}$} & \multicolumn{4}{|c|}{ Uptake of HIV testing } & \multicolumn{3}{|c|}{ Sought help during last STI infection } & \multirow[t]{2}{*}{ Total } \\
\hline & No & Yes & P-value & Total & No & Yes & P-value & \\
\hline No & 98.2 & 95.6 & 0.036 & 97.7 & 98.1 & 97.6 & 0.790 & 97.8 \\
\hline Yes & 0.4 & 4.4 & & 2.3 & 2.0 & 2.4 & & 2.3 \\
\hline Total & 100.0 & 100.0 & & 100.0 & 100.0 & 100.0 & & 100.0 \\
\hline Number of women & 592 & 169 & & 761 & 202 & 566 & & 768 \\
\hline
\end{tabular}

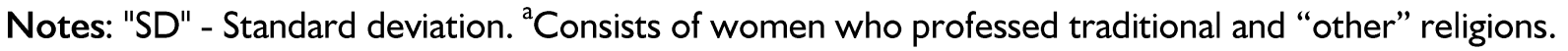


Among all women, the prevalence of HIV testing uptake and STI treatment were $22 \%$ and $74 \%$ respectively. In the overall sample, $56 \%$ of the women lived in urban areas while $44 \%$ lived in rural areas. A higher percentage of women with HIV testing uptake $(58 \%)$ were from urban areas. Likewise, more than half $(62 \%)$ of the women that sought treatment for STI lived in urban areas. The mean age of the women was 33 years old. About $85 \%$ of the women were between 25 and 39 years old. The rest of women were under 24 years old. Women who reported HIV testing uptake were mostly between $25-34$ years old (57\%) while $42 \%$ and $43 \%$ of women who reported no HIV testing were between the age groups: 25 - 34 years and 3549 years old respectively. Almost half of the women who sought treatment for STI (48\%) were between 25-34 years old, while almost half of the women (49\%) who did not seek treatment for STI were in the oldest age category (35-49 years). Prevalence of HIV testing uptake and STI treatment were lowest among the youngest women (I5-24 years).

Forty percent of the women who reported recent HIV testing were in the highest wealth quintile with only $7 \%$ in the lowest quintile; among women with no HIV testing uptake , $26 \%, 24 \%$ and $23 \%$ were from the fourth, highest, and second quintiles respectively. Similarly, the percentage of women who sought treatment for STI increased with income ranging from $6 \%$ in the lowest wealth quintile to $33 \%$ in highest quintile. Among women who did not seek treatment for STI, nearly $40 \%$ belonged to the second wealth quintile, the least percentage being among women from the highest wealth quintile (II\%).

More than half of the women who reported HIV testing uptake $(68 \%)$ and who sought treatment for STI (57\%) completed secondary education and higher, while $33 \%$ of the women who did not report HIV testing uptake had no education and $52 \%$ of this group of women also did not seek STI treatment.

Majority (79\%) of women who reported HIV testing uptake were Christians, others were mainly of the Islamic religion (21\%). We observed the same pattern among women that reported no HIV testing uptake where $63 \%$ were Christians, and $37 \%$ of the Islamic religion. Similarly, Christianity was the most represented religion reported both among women who sought STI treatment (72\%) and among those who did not $(51 \%)$. More than half of the women (52\%) reporting HIV testing uptake had visited a health facility in the past 12 months. Among women that reported no HIV testing uptake, $54 \%$ had not visited a health facility up to 12 months prior to the survey. More than half $(52 \%)$ of the women who sought treatment for STI had visited the health facility 3863 in the 12 months preceding the survey; $62 \%$ of women who did not seek treatment for STI had visited a health facility 12 months before the survey.

Over half of the women with HIV testing uptake and no HIV testing uptake had some level of autonomy (52\% and $54 \%$ respectively). A higher proportion of women $(59 \%)$ that sought treatment for STI had autonomy, whereas majority of the women that did not seek treatment for STI had no autonomy (59\%). Most women seemed to know where to get tested for HIV (89\%). All women (I00\%) who had undertaken HIV testing reported knowing where to receive the test, while $87 \%$ of women reporting no HIV testing uptake knew where to get tested for HIV. Likewise, $93 \%$ of women who sought treatment for STI and $81 \%$ of women who did not seek treatment for STI reported knowing where to get tested for HIV.

Condom use was very low among the participants - $96 \%$ of women who reported HIV testing uptake, and $98 \%$ of women who reported no HIV testing uptake had not used condoms in the 12 months preceding the survey. We observed the same pattern among women who sought treatment for STI and those who did not.

Table 2 presents the prevalence of HIV testing uptake and STI treatment by key characteristics of the women. In general, prevalence of STI treatment was higher (74\%) than the prevalence of HIV testing uptake (22\%) among women. HIV testing uptake was slightly lower (20\%) among women who had experienced any form of IPV than among their counterparts with no history of IPV (25\%). We observed a contrary pattern for STI treatment, where prevalence was higher (75\%) among women who had experienced any form of IPV than among women with no history of IPV (70\%). Prevalence of both HIV testing uptake (25\%) and STI treatment (80\%) were higher among women living in urban areas than among women living in rural areas. HIV testing uptake and STI treatment were more prevalent among women between 25 and 34 years old $(28 \%$ and $79 \%$, respectively). Prevalence of HIV testing uptake and STI treatment were directly proportional to wealth quintile, ranging from 12\% among women in the lowest wealth quintile to $35 \%$ among women in the highest wealth quintile for HIV testing uptake and $55 \%$ to $88 \%$ for STI treatment.

Similarly, prevalence of HIV testing uptake and STI treatment were directly proportional to women's level of education. Prevalence of HIV testing uptake were $9 \%, 18 \%$ and $32 \%$ among women with none, primary and secondary and higher education respectively; for STI treatment, prevalence was 52\%, $78 \%$ and $85 \%$ respectively. HIV testing uptake and STI treatment were more prevalent among women 
whose religion was Christianity $(27 \%$ and $80 \%$ respectively) and among women who had no autonomy ( $23 \%$ and $81 \%$, respectively).

Table 2. Percentage of married women reporting STI in the 12 months preceding the survey and whether they had an HIV test or sought treatment for STI, Nigeria Demographic and Health Survey, 20I 3

Characteristics

Intimate partner violence

Emotional IPV

Yes

No

Experienced physical IPV

Yes

No

Experienced sexual IPV

Yes

No

Experienced any form of IPV

Yes

No

Place of residence

Urban

Rural

Age group

15-24

25-34

35-49

Region of residence

North Central

North East

North West

South East

South South

South West

Wealth quintile

Lowest

Second

Third

Fourth

Highest

Education

None

Primary

Secondary and higher

Religion*
Percent who had tested for HIV past 12 months $(95 \% \mathrm{Cl})$

$19.8[16.0,23.5]$

$25.4[20.7,30.1]$

$20.1[15.9,24.3]$

$24.0[19.8,28.1]$

20.3 [15.1, 25.4]

$23.1[19.5,26.7]$

$20.2[16.5,23.8]$

$25.4[20.4,30.4]$

$24.6[20.2,29.0]$

$19.8[15.8,23.9]$

23.2 [I5.I, 3।.2]

$27.5[22.7,32.3]$

I6.2 [I2.I, 20.3]

31.1 [22.7, 39.5]

$23.7[16.3,31.0]$

$8.9[5.4,12.4]$

$28.8[21.3,36.2]$

$34.9[20.0,49.7]$

$32.8[21.0,44.6]$

II.5 [4.3, I8.8]

I $4.9[9.6,20.3]$

20.5 [14.2, 26.8]

$22.5[16.0,29.0]$

$34.6[27.7,4 I .4]$

$9.2[5.4,13.0]$

I $7.8[11.9,23.6]$

$32.4[27.6,37.2]$
Percent who sought treatment for STI $(95 \% \mathrm{Cl})$

$74.2[70.1,78.4]$

$73.0[68.2,77.8]$

8I.I [77.I, 85.0]

$73.2[68.9,77.5]$

$73.9[68.3,79.6]$

$73.6[69.8,77.4]$

$74.6[70.7,78.6]$

$72.2[67.1,77.3]$

$80.1[76.1,84.1]$

$67.4[62.7,72.1]$

$76.8[68.8,84.7]$

$78.9[74.6,83.3]$

$68.9[61.6,72.1]$

$82.6[75.8,89.5]$

$81.8[75.2,88.5]$

$53.9[47.8,60.0]$

$86.7[81.2,92.2]$

$79.1[66.4,91.7]$

$85.9[77.2,94.7]$

$55.1[43.8,66.4]$

$51.7[44.2,59.2]$

$78.4[72.0,84.8]$

$84.6[78.9,90.2]$

$88.4[83.8,93.0]$

$51.8[45.2,58.3]$

$77.6[71.3,84.0]$

$85.0[81.8,89.0]$ 
Percent who had

\section{Characteristics \\ Christianity \\ Islam}

\section{Autonomy}

No

Yes

All women

Number of women tested for HIV past 12

months $(95 \% \mathrm{Cl})$

$26.9[22.9,30.8]$

$13.7[9.5,17.9]$

$23.2[19.0,27.5]$

$21.6[17.3,25.9]$

$22.2(19.2,25.2)$

761

\author{
Percent who sought treatment for \\ STI $(95 \% \mathrm{Cl})$ \\ $80.2[76.7,83.8]$ \\ $6 I . I[55.2,67.0]$
}

$80.9[77.0,84.9]$

$65.1[60.1,70.0]$

$73.7[70.6,76.8]$

768

Note: *Other religion excluded due to few $(n=6)$ cases

Table 3 presents results from the multivariate analysis of the association between IPV and HIV testing uptake and, between IPV and STI treatment within the sample. We observed reduced odds of recent HIV testing uptake among women who had experienced IPV; however, the odds ratios were not statistically significant. Likewise, we found that IPV experience was associated with increased odds of recent STI treatment; however, these were not statistically significant. Women who lived in the North West region were $73 \%(\mathrm{OR}=0.27, \mathrm{Cl}=0.14$ $0.53 ; \mathrm{p}<0.00 \mathrm{I})$ and $77 \%(\mathrm{OR}=0.23, \mathrm{Cl}=0.12-0.46$; $\mathrm{p}<0.00 \mathrm{I}$ ) less likely to report HIV testing uptake and STI treatment respectively, compared to their counterparts from the North Central region. We observed a dose-response relationship between wealth quintiles and STI treatment. We observed that women in the third, fourth and highest quintiles were 3 times $(\mathrm{OR}=3.06, \mathrm{Cl}=1.43-6.56 ; \mathrm{p}<0.01), 5$ times
$(\mathrm{OR}=5.34, \mathrm{Cl}=2 . \mathrm{II}-\mid \mathrm{3} .54 ; \mathrm{p}<0.00 \mathrm{I})$ and 8 times $(\mathrm{OR}=8.0 \mathrm{I}, \mathrm{Cl}=2.94-2 \mathrm{I} .87 ; \mathrm{p}<0.00 \mathrm{I})$ more likely to seek treatment for STI, respectively, than their counterparts in the lowest wealth quintile. However, we did not find statistically significant association between wealth quintile and HIV testing uptake. Rather, we found that women who completed secondary education and higher had almost 3 fold increased odds of HIV testing uptake compared to women with no form of education $(O R=2.68$, $\mathrm{Cl}=$ I.33-5.37; $\mathrm{p}<0.0 \mathrm{I})$. In addition, women who visited a heath facility in the 12 months preceding the survey had almost 2-fold increased odds of HIV testing uptake compared to their counterparts who had not visited a health facility in the past 12 months.

Autonomy was not associated with uptake of HIV testing, although it was significantly associated with increased odds of STI treatment among $(\mathrm{OR}=1.59$, $\mathrm{Cl}=\mathrm{I} .05-2.49 ; \mathrm{p}<0.0 \mathrm{I})$. 
Table 3. Unadjusted and adjusted models of the association between uptake of HIV testing and STI treatment among married women who reported STI during the I2 months prior to the Nigeria Demographic and Health Survey, 2013

\section{Uptake of HIV testing Update of STI treatment} Unadjusted ORs $[95 \%$ Adjusted ORs $[95 \%$

\section{Characteristics}

Intimate Partner $\mathrm{Cl}]$

\section{$\mathrm{Cl}]$}

\section{Violence}

None

Emotional

Physical

Sexual

Place of residence

Urban

Rural

Age group

15-24

25-34

$35-49$

Region of residence

North Central

\section{North East}

North West

South East

South South

South West

\section{Wealth quintile}

\section{Lowest}

Second

Third

Fourth

Highest

$$
\begin{gathered}
\text { Ref } \\
0.64(0.36, I .13) \\
0.79(0.48, I .31) \\
0.75(0.49, I .13)
\end{gathered}
$$

Ref

$0.76(0.54,1.07)$

\section{Ref}

$1.35(0.89,2.03)$

$0.64(0.38,1.09)$

\section{Ref}

$0.69(0.39,1.20)$

$0.22(0.12,0.39)$ ****

$0.90(0.53,1.52)$

$1.19(0.57,2.48)$

$\mathrm{I} .08(0.56,2.07)$

\section{Ref}

$1.35(0.60,3.03)$

1.98 (0.89 4.37)

$2.23(\mathrm{I} .0 \mathrm{I}, 4.89)$ *

$4.05(1.90,8.64)^{* * * *}$
Ref

$0.58(0.31,1.11)$

$0.63(0.36,1.10)$

$0.88(0.54,1.42)$

Ref

I.5। $(0.90,2.54)$

Ref

$1.20(0.67,2.15)$

$0.73(0.39,1.34)$

Ref

$0.93(0.47,1.82)$

$0.27(0.14,0.53)^{* * * *}$

$0.79(0.42,1.46)$

$1.56(0.65,3.74)$

$0.86(0.39,1.88)$

Ref

I. $23(0.50,3.04)$

$1.04(0.41,2.65)$

I. $14(0.42,3.1 \mathrm{I})$

I.76 $(0.63,4.92)$

Unadjusted ORs $[95 \%$ Adjusted ORs [95\% Cl] $\mathrm{Cl}]$

$$
\begin{aligned}
& \text { Ref } \\
& \text { I.03 (0.62, I.72) } \\
& \text { I.25(0.77, 2.02) } \\
& \text { I.07 (0.73-I.57) }
\end{aligned}
$$

Ref

0.5 I $(0.37-0.7 \mathrm{I})^{* * * *}$

Ref

I. $13[0.68,1.88]$

$0.61[0.37,0.99]^{*}$

Ref

$0.91[0.47,1.75]$

$0.24[0.14,0.41]^{* * * *}$

$1.34[0.68,2.63]$

$0.76[0.31,1.82]$

$1.26[0.54,2.96]$

Ref

$0.84[0.49,1.44]$

$2.94[1.63,5.28]^{* * * *}$

$4.37[2.35,8.14]^{* * *}$

$6.18[3.28,11.65]^{* * * *}$
Ref

$1.02[0.55,1.87]$

$0.75[0.42,1.33]$

I. $27[0.79,2.04]$

Ref

I.70 [0.97, 2.99]

Ref

I. $10[0.60,2.00]$

$0.63[0.35,1.15]$

Ref

I.4I [0.66, 3.05]

$0.23[0.12,0.46]^{* * * *}$

$1.00[0.45,2.25]$

$0.36[0.13,1.00]$

$0.50[0.18,1.34]$

Ref

$0.92[0.47,1.79]$

$3.06[1.43,6.56]^{* *}$

$5.34[2.11,13.54]^{* * * *}$

$8.01[2.94,21.87]^{* * * *}$

http://aps.journals.ac.za 


\begin{tabular}{|c|c|c|c|c|}
\hline \multirow[b]{2}{*}{ Characteristics } & \multicolumn{2}{|l|}{ Uptake of HIV testing } & \multicolumn{2}{|c|}{ Update of STI treatment } \\
\hline & $\begin{array}{l}\text { Unadjusted ORs [95\% } \\
\mathrm{Cl}]\end{array}$ & $\begin{array}{l}\text { Adjusted ORs }[95 \% \\
\mathrm{Cl}]\end{array}$ & $\begin{array}{l}\text { Unadjusted ORs [95\% } \\
\mathrm{Cl}]\end{array}$ & Adjusted ORs $[95 \% \mathrm{Cl}]$ \\
\hline \multicolumn{5}{|l|}{ Education } \\
\hline None & Ref & Ref & Ref & Ref \\
\hline Primary & $2.13(1.17,3.87)^{*}$ & $1.59(0.79,3.22)$ & $3.24[2.07,5.07]^{* * * *}$ & $1.79[1.00,3.21]$ \\
\hline Secondary and above ${ }^{a}$ & $4.73(2.87,7.79)^{* * * *}$ & $2.68(1.33,5.37)^{* *}$ & $5.53[3.74,8.16]^{* * * *}$ & $1.71[0.92,3.18]$ \\
\hline \multicolumn{5}{|l|}{ Religion } \\
\hline Christianity & Ref & Ref & Ref & Ref \\
\hline Islam & $1.00(0.65,1.52)$ & $0.97(0.55,1.70)$ & $0.39(0.28,0.54)^{* * * *}$ & $1.38[0.81,2.36]$ \\
\hline \multicolumn{5}{|l|}{$\begin{array}{l}\text { Visited health facility } \\
\text { (last } 12 \text { months) }\end{array}$} \\
\hline No & Ref & Ref & Ref & Ref \\
\hline Yes & $1.41(0.94,2.10)$ & $1.56(1.03-2.38)^{*}$ & $2.05[1.45,2.90]^{* * *}$ & $\mathrm{I} .52[0.96,2.4 \mathrm{I}]$ \\
\hline \multicolumn{5}{|l|}{ Autonomy } \\
\hline No & Ref & Ref & Ref & Ref \\
\hline Yes & $1.10(0.78,1.56)$ & $0.74(0.49,1.12)$ & $2.35[1.68,3.29]^{* * * *}$ & $1.59[1.05,2.41]^{* * *}$ \\
\hline \multicolumn{5}{|l|}{$\begin{array}{l}\text { Knows a place to get } \\
\text { HIV test }\end{array}$} \\
\hline No & - & - & Ref & Ref \\
\hline Yes & - & - & $3.27(2.11-5.07)^{* * * *}$ & $1.29(0.72,2.32)$ \\
\hline Number of women & 754 & 638 & 761 & 739 \\
\hline Likelihood Ratio Chi2 & & 89.24 & & 190.80 \\
\hline Prob > Chi2 & & 0.000 & & 0.000 \\
\hline
\end{tabular}




\section{Discussion}

Our study found high prevalence of IPV among married Nigerian women with a recent history of STI. Given that all the women in our study had recent STI and that IPV and STI were assessed retrospectively within the same period (12 months preceding the survey), our finding corroborates with results from other studies that have found associations between IPV and STI (Wandera, 2010; Manfrin-Ledet, Porche and Westbrook, 20I5).

We also observed low prevalence of HIV testing uptake, and high prevalence of STI treatment among the women. The low HIV testing uptake may be due to factors related to norms and gender roles that preclude women from decision-making, and require men to make decisions about their partners' health care needs. Given that HIV testing is a preventive behavior, men may not see a need for it, unless there are obvious reasons to believe that their partners may be sick from infection with HIV. In contrast, men may have allowed their partners to seek treatment for STI because the women were symptomatic and already sick from the infection, hence, needed to be treated.

We did not find any significant association between IPV and HIV testing uptake, and between IPV and STI treatment among the women, although we observed an inverse but insignificant association between IPV and HIV testing uptake among the women. Decision about getting tested for HIV maybe their husbands' to make as a high proportion (46\%) of women reported that their husbands/partners made decisions about their healthcare. Furthermore, given that women in this study may be at increased risk for STI and HIV infection, they may be worried about the likelihood of experiencing increased IPV should they test positive for HIV, hence they may avoid HIV testing. Studies have found increased prevalence of IPV experience after women disclosed positive HIV test results to their partners (Shamu et al. 2014; Colombini et al. 2016; Watts and Seeley, 2014; Bonnes, 2016). Another study found low prevalence of HIV testing among women experiencing IPV and at increased risk for HIV infection (Etudo et al. 2017).

While we observed quite high prevalence of STI treatment seeking among the women, we did not find any significant association between IPV experience and STI treatment. There could be several reasons for this observation. First, we observed increased but non-significant odds of STI treatment. This may have been due to our small sample size and insufficient power to detect a notable effect. Second, although both IPV and STI treatment were assessed with reference to the past 12 months, it is uncertain whether IPV experience occurred before STI or vice versa. STI could have occurred independent of IPV as we observed that both STI treatment and non-treatment were most prevalent among women who reported no experience of IPV; we also did not observe any difference in STI treatment seeking among women by IPV experience status.

\section{Correlates of HIV testing uptake and STI treatment}

We observed higher likelihood of HIV testing with higher educational attainment, and higher likelihood of STI treatment with higher income. Women who completed secondary education or higher were more likely to report HIV testing uptake than those with no form of education. This is in agreement with findings from the literature (Lepine, Terris-Prestholt and Vickerman 2015).Women who are more educated tend to have more exposure and knowledge about the negative health impact of non-testing. Additionally, educated women are more likely to invest in their own health and to understand the importance of knowing their HIV status. However, we did not observe the same for STI treatment, as we observed attenuated statistical significance in the adjusted model.

Women in the highest wealth quintile were 8 times significantly more likely to seek STI treatment compared to their peers in the lowest wealth quintile. Women who have more disposable income are more likely to afford the costs associated with seeking treatment, than poor women. Expenses involved in seeking treatment may include transportation, prescription and hospital/clinic costs. Besides the financial advantage and the myriad of treatment choices that wealth may afford a woman, the choice to seek STI treatment may also be because of the signs, symptoms and discomfort that is often associated with STIs. Increased discomfort may lead to increased perceived severity of the consequences of not seeking treatment, which then increases motivation to seek treatment. This is slightly different from HIV testing, where the women may not feel any urgent need to seek HIV testing due to a perceived low risk for HIV infection.

HIV testing uptake was significantly associated with past 12 months health facility visit among women, compared to their counterparts who did not visit a health facility in the past year. This is reasonable, as women who are connected to the health system are more likely to receive necessary preventive health services than women who are not connected to the health system. Nonetheless, less than half of the women in our study had visited a health facility in the 12 months preceding the survey. This has several public health implications as contact 
with health facilities provides window of opportunity to educate women on protective sexual health behaviors, including introducing modern contraceptives. The main route through which access to health services impacts on HIV infection is through the non-treatment of STls. If women are not connected to the health system, the opportunity to treat any STI may be missed. Most importantly, considering that the women were high risk (high IPV prevalence and history of STI), contact with the health system provides opportunities to intervene with them and to address other risks for adverse reproductive and sexual health outcomes.

Autonomy was significantly associated with almost two-fold increased odds of STI treatment among women. Our autonomy variable was based on women's involvement in decision making regarding their health care. Women who were involved in making these decisions were categorized as being autonomous. It is thus reasonable for this group of women to be more likely to seek treatment for STI than women who are not involved in making decisions regarding their health care. This however has some implications for the sexual health of women who experience IPV as they are less autonomous (Wekwete et al., 2014) and may be less likely to seek STI treatment than women who do not experience IPV.

\section{Conclusion}

IPV was associated with decreased odds of HIV testing uptake and increased odds of STI treatment among women reporting recent STI, although these associations were not statistically significant. Nonetheless, we observed very high prevalence of IPV among this population of high-risk women. This has several implications. First, IPV is associated with many adverse physiological, mental and reproductive health outcomes that affect women's quality of life, influences their full and effective participation in the society and undermines the achievement of the SDG 5 - "achieve gender equality and empower women and girls" (Caldwell, Swan and Woodbrown, 20I2; Roldos and Corso, 20/3).

Second, more than half of the women in this study were between 25 and 34 years old; experiencing IPV at this prime age negatively affects economic growth. IPV is associated with high economic, labor, and health care costs as women who experience IPV record higher absenteeism from work, higher job turn-over, lower earning capacity, billions of dollars in days lost from paid work and more intensive utilization of health care services. These reduces human capital and divert already scarce public resources for essential health, security and infrastructure services within communities
(International Center for Research on Women (ICRW), 20I8; Duvvury et al. 2013). It is therefore imperative to continue to seek ways to improve early identification of women at risk of experiencing IPV and intervene in their situations as early as possible.

Majority of the women in our study knew where to get tested for HIV, yet HIV testing uptake was low. This validates the notion that knowledge does not always translate to behavior change especially in domestic contexts characterized by high levels of emotional, physical and/or sexual violence. There is therefore a great need to better understand the barriers to HIV testing uptake and STI treatment among high-risk women and to intervene accordingly.

\section{References}

Bamiwuye, S.O. and Odimegwu, C. (2014). Spousal violence in sub-Saharan Africa: does household poverty-wealth matter?. Reproductive Health, II (I), 45-55.

Bonnes, S. (2016). Education and Income Imbalances Among Married Couples in Malawi as Predictors for Likelihood of Physical and Emotional Intimate Partner Violence. Violence and Victims, 3I(I), 5I69.

Butsashvili, M., Kajaia, M., Kamkamidze, G., Tchendjou, P., Desgrees du Lou, A., Dabis, F. and Orne-Gliemann, J. (20|4). Factors Associated with HIV Testing History among Pregnant Women and Their Partners in Georgia: The ANRS 12127 Prenahtest Trial. AIDS Research and Treatment, 20I4, I-6.

Caldwell, J.E., Swan, S.C. and Woodbrown, V.D. (20/2). Gender differences in intimate partner violence outcomes. Psychology of Violence, 2(I), 42-57.

Colombini, M., James, C., Ndwiga, C. and Mayhew, S.H. (20I6). The risks of partner violence following HIV status disclosure, and health service responses: narratives of women attending reproductive health services in Kenya. Journal of the International AIDS Society, I ( (I), 20766.

Duvvury, N., Callan, A., Carney, P. and Raghavendra, S. (20/3). Intimate Partner Violence: Economic Costs and Implications for Growth and Development. Women's Voice, Agency and Participation Research Series, 3, I-97.

Etudo, O., Metheny, N., Stephenson, R. and Kalokhe, A.S. (20I7). Intimate partner violence is linked to less HIV testing uptake among high-risk, HIVnegative women in Atlanta. AIDS Care, 29(8), 953-956.

Gazimbi, M.M. and Monica, A.M. (2017). A multilevel analysis of the determinants of HIV testing in Zimbabwe: Evidence from the demographic and 
health surveys. HIV/AIDS Research and Treatment $4(I),|4-3|$.

Hess, K.L., Javanbakht, M., Brown, J.M., Weiss, R.E., Hsu, P. and Gorbach, P.M. (20|2). Intimate partner violence and sexually transmitted infections among young adult women. Sexually transmitted diseases, 39(5), 366-37I.

International Center for Research on Women (2018).

Estimating the Costs and Impacts of Intimate Partner Violence in Developing Countries: A Methodological Resource Guide [Homepage of ICRW], [Online]. Available: https://www.icrw.org/wp-

content/uploads/2016/10/Estimating-the-Costs-

and-Impacts-of-Intimate-Partner-Violence-in-

Developing-Countries-A-Methodological-

Resource-Guide.pdf. [Accessed 5 February 2018].

Kazmerski, T., McCauley, H.L., Jones, K., Borrero, S., Silverman, J.G., Decker, M.R., Tancredi, D. and Miller, E. (20I5). Use of reproductive and sexual health services among female family planning clinic clients exposed to partner violence and reproductive coercion. Maternal and child health journal, I9(7), I490-I496.

Kharsany, A.B. and Karim, Q.A. (20I6). HIV Infection and AIDS in Sub-Saharan Africa: Current Status, Challenges and Opportunities. The open AIDS Journal, IO(I), 34-48.

Lepine, A., Terris-Prestholt, F. and Vickerman, P. (20I5). Determinants of HIV testing among Nigerian couples: a multilevel modelling approach. Health policy and planning, 30 (5), 579-592.

Li, Y., Marshall, C.M., Rees, H.C., Nunez, A., Ezeanolue, E.E. and Ehiri, J.E. (20|4). Intimate partner violence and HIV infection among women: a systematic review and meta-analysis. Journal of the International AIDS Society, I 7(I), 18845.

Mahande, M.J., Phimemon, R.N. and Ramadhani, H.O. (20I6). Factors associated with changes in uptake of HIV testing among young women (aged 15-24) in Tanzania from 2003 to 20I2. Infectious diseases of poverty, $5(\mathrm{I}), 0180-3$.

Manfrin-Ledet, L., Porche, D.J. and Westbrook, S. (20I5). Relationship of Intimate Partner Violence, HIV Risk Behaviors, and Powerlessness in AfricanAmerican Women of Childbearing Age. Journal of University of Ibadan, Nigeria. BMC Women's Health, I4(I3I), I-8.

UNAIDS. (20I4). Gap Report: Beginning of the end of the AIDS Epidemic. [online] Available at: http://files.unaids.org/en/media/unaids/contentasse ts/documents/unaidspublication/20I4/UNAIDS_G ap_report_en.pdf. [Accessed 20 January 2018]

Gender Analysis Toolkit For Health Systems I Jhpiego. (20I8). Gender Analysis | Gender Analysis Toolkit For Health Systems | Jhpiego.
National Black Nurses' Association: JNBNA, 26(I), 40-49.

McGrane Minton, H.A., Mittal, M., Elder, H. and Carey, M.P. (20I6). Relationship Factors and Condom Use Among Women with a History of Intimate Partner Violence. AIDS and behavior, 20(I), 225-234.

National Population Commission (NPC) [Nigeria] and ICF International (20I4). Nigeria Demographic and Health Survey 2013. NPC and ICF International, Rockville Maryland.

Overstreet, N.M., Willie, T.C., Hellmuth, J.C. and Sullivan, T.P. (20I5) Psychological intimate partner violence and sexual risk behavior: examining the role of distinct posttraumatic stress disorder symptoms in the partner violence-sexual risk link. Women's Health Issues, 25(I), 73-78.

Roldos, M.I. and Corso, P. (20/3). The economic burden of intimate partner violence in Ecuador: setting the agenda for future research and violence prevention policies. The Western Journal of Emergency Medicine, 14 (4), 347-353.

Shamu, S., Zarowsky, C., Shefer, T., Temmerman, M. and Abrahams, N. (20|4). Intimate partner violence after disclosure of HIV test results among pregnant women in Harare, Zimbabwe. PLoS ONE, 9(I0), el 09447.

Tanimu, T.S., Yohanna, S. and Omeiza, S.Y. (20I6). The pattern and correlates of intimate partner violence among women in Kano, Nigeria. African Journal of Primary Health Care \& Family Medicine, 8 (I), el-e6.

Teitelman, A.M., Calhoun, J., Duncan, R., Washio, Y. and McDougal, R. (20/5). Young women's views on testing for sexually transmitted infections and HIV as a risk reduction strategy in mutual and choice-restricted relationships. Applied Nursing Research, 28(3), 2I5-22I.

Udo, I.E., Lewis,J.B., Tobin, J.N. and Ickovics, J.R. (2016). Intimate Partner Victimization and Health Risk Behaviors Among Pregnant Adolescents. American Journal of Public Health, 106 (8), I4571459.

Umana, J.E., Fawole, O.I. and Adeoye, I.A. (20|4). Prevalence and correlates of intimate partner violence towards female students of the [online] Available at: https://gender.jhpiego.org/analysistoolkit/genderanalysis/ [Accessed 20 January 20।8].

Wandera, S.O., Ntozi, J.P.M., and Kwagala, B. (2010). Spousal sexual violence, sexual behavior and sexually transmitted infections among evermarried women in Uganda. African Population Studies, 24(I-2); 70-87.

Watts, C., and Seeley, J. (2014). Addressing gender inequality and intimate partner violence as critical 
barriers to an effective HIV response in subSaharan Africa. Journal of the International AIDS Society, I7(I), 19849.

Wekwete, N.N., Sanhokwe, H., Murenjekwa, W., Takavarasha, F. and Madzingira, N. (20I4). The Association between Spousal Gender Based
Violence and Women's Empowerment among Currently Married Women aged I5-49 in Zimbabwe: Evidence from the 20l0-II Zimbabwe Demographic and Health Survey. African Population Studies, 28(3), I4I3-I43I. 